\title{
Constructing Personal Epistemologies: Cultural and Methodological Considerations
}

\author{
Commentary on Tafreshi, Khalil, and Racine
}

Ashley E. Maynard Devin E. Barney

Department of Psychology, University of Hawai'i, Honolulu, HI, USA

\author{
Keywords \\ Epistemology · Qualitative methods · Culture, knowledge
}

As humans, we can become aware of ourselves as knowers. We can identify sources of our knowledge, how knowledge is constructed in the mind, and how knowledge changes. Enlightenment principles of reason, science, humanism, and progress brought forth in the 18th century help us to organize explorations of our own minds and to interrogate our own knowledge, changing our ideas when confronted with new information or frames of mind. Epistemologies are influenced by language and culture, and, as with all phenomena affected by cultural processes, epistemologies are also affected by macrolevel factors like historical time and microlevel factors like gender.

\section{How Do People Think about Their Own Knowledge and Ways of Knowing?}

Asking people how they think about knowledge gives insights into how their minds work, adding to the discussion of what knowledge and the mind entail in a general sense. Asking people questions about where their knowledge comes from tells us something about how they know their own minds. The question of how epistemologies develop is a compelling one, and exploring personal epistemologies (PEs) as ways of knowing adds to the story about how people develop a knowledge base and use that knowledge in interactions. The ability to articulate where our knowledge comes from appears to be uniquely human, and it is worth understanding how personal epistemologies develop and are used because they are tied to learning strategies, dispositions for learning, and cognitive reasoning (Hofer, 2001; Kuhn, 1999). PEs also have implications for assessing knowledge we come into contact with in society, af-

\begin{tabular}{lll}
\hline KARGER & & Ashley E. Maynard \\
E-Mail karger@karger.com & & Department of Psychology, University of Hawai’i \\
www.karger.com/hde & Sakamaki C-400 & Honolulu, HI 96822 (USA) \\
& E-Mail amaynard@ @awaii.edu
\end{tabular}


fecting decisions about how to handle disputes, how to raise children, and how to approach problems like climate change or make other political decisions. Knowing about PEs tells us how people's beliefs about knowledge and authorities of knowledge affect what they make of information. Knowing how different minds work means that we can make inferences about how people will take in new information, reason, make decisions, interact with others, and the like.

Tafreshi, Khalil, and Racine (this issue) contribute to a greater understanding of how minds work and what knowledge is as they explore women's PEs. The main purpose of the article is to explore, using phenomenological qualitative methodology, how women's PEs fit into a typology previously devised by others. Tafreshi and colleagues asked participants, all mothers of young children: "What has been your experience as a learner, thinker, or knower? How have your ways of thinking, knowing, and learning changed over time, and which people were important to those changes? Do you think of yourself primarily as a speaker or a listener? How do you handle situations where there is a conflict of opinion? Do you believe there is one correct answer in all cases?"

\section{Patterns of Knowing Revealed in Quantitative Approaches}

There are five epistemological patterns described by the authors in their study based on work with women by Belenky, Clinchy, Goldberger, and Tarule (1986). These range from voicelessness (silent knowers) to having a voice (all other categories), from liking correct answers and being uncomfortable with gray areas (received knowers), to questioning authority and following gut instincts with knowledge tied to emotion and experience (subjective knowers), to complex views of knowledge and truth and empathy with others (procedural knowers), and finally to realizing that one is the constructor of knowledge (constructed knowers). Received knowers might be uncomfortable with gray areas and may seek authority figures to give them correct answers. Subjective knowers may question authority and follow their gut instincts when faced with a dilemma, and therefore they and received knowers might be manipulated by an emotional appeal that questions the authority of a particular source and gives authority to - from those knowers' point of view - a more credible source. Procedural knowers accept that knowledge and truth are complex, and they understand that there is not always one right answer to a problem. They respect expertise and do not believe a person's gut instinct is always correct. Therefore, they might be convinced to drop their gut instincts about a question and listen to reason. Constructed knowers acknowledge their own contribution in the construction of their own knowledge. They view learning as constant and endless. They might be interested in becoming a part of an activity that helps others come to understand a shared, reasoned point of view.

These patterns are not seen as a scale upon which one is ranked, and it is not clear that people develop from one stage to the next. In fact, Tafreshi and colleagues' use of qualitative inquiry lends us new insight that quantitative methods may have overlooked. For example, their qualitative interviews allowed us to see how knowledge use does not occur in a vacuum. There may be different patterns of knowledge use by the same individuals in different settings, as the situation might demand. Along these same lines, Tafreshi and colleagues also highlight that scientific reasoning is not an ideal mode in every situation, and sometimes receiving unquestioned knowledge 
from an authority is harmless when it does not cause dissonance with the rest of one's life or hinder the progress of others.

\section{Qualitative Methods in the Study of Knowing}

We agree with the investigators that qualitative methods are essential in the study of women's PEs. We were surprised that research into PEs has been predominantly quantitative. The authors correctly assert that aggregate-level statistics cannot tell us anything about specific individuals in the population. In fact, statistical analyses do not tell us what is true for any particular and certainly not "all" members of a group. Indeed, microgenetic methods may be promising in discovering more about how beliefs about knowledge change over time, as such methods are in investigating other aspects of development (Maynard, 2009). The development of PEs should be studied over time and in different contexts.

Methods of qualitative inquiry allow us access to these different contexts and can be parsed into meaningful units of analysis. The vast array of settings consists of actors with different motives and purposes acting within a specific ecology that operates with its own tasks to manage, scripts for conduct, and underlying cultural values all bounded in a particular time (Gallimore, Goldenberg, \& Weisner, 1993). Qualitative methods compel us to inspect these different elements of setting to see all that can occur within an assumed category or labeled phenomenon. Phenomenological interview techniques, like the ones conducted by Tafreshi et al. (this issue) peer beyond quantitative codings and shed light on unexamined spectra of experiences. For example, it is assumed with Belenky and colleagues' (1986) work that received knowers wholeheartedly trust authority figures to provide reliable knowledge, tend to need external validation of ideas, and see knowledge as having correct answers (black and white thinking). While most of that may be true for a received knower, Anya, Tafreshi and colleagues (this issue) found that this assumed profile could not have been further from the experience of the rebellious Jenny - who distrusted authority but believed that knowledge was passed down as hearsay, and thus she fit the category of a received knower. Even Anya who matched much of the received knower profile demonstrated cross-category thinking when she acknowledged that thinking from multiple perspectives was possible though not preferred. Though these women shared a quantitative category label, their qualitatively provided experiences demonstrated a broad range within that category. Further, we can look to these qualitative accounts to observe the sociocultural and historic elements of setting that may have contributed to PE development. For instance, in Tara's account, she lamented her history within university settings in which she came to adopt a subjective knower epistemology. Access to the experience of settings in this way broadens our understanding of PEs and their development and pushes us to think more critically about the boundaries of taxonomies we render from only quantitative results.

\section{Language and Culture in Epistemological Stances}

In broadening our perspective, Tafreshi and colleagues make the point that PEs are socioculturally situated and are rooted in subjective individual experiences, and it is worth thinking about the cultural processes that help form PEs in the mind. Cul- 
tural expectations, goals, and values related to knowledge may be revealed linguistically. Deploying interview techniques or other such qualitative methods affords us the opportunity to probe this kind of expression.

\section{Linguistic Aspects of Knowing}

About $25 \%$ of the world's languages grammaticalize information source (Aikhenvald, 2004), where a speaker reveals morphologically and not with separate lexical items that information is reported, rather than observed firsthand. These are called evidentials, and English does not use them. Franz Boas (1942) first described grammatical evidentials in Kwakiutl, and linguists later found them in many other Native American languages as well. The kind of precision required in such languages is not expected in English, where it is optional to say, with extra words, that information was reported and not gained through first-hand experience. How might the epistemologies of people who constantly index evidentiality in grammatical morphemes differ from the epistemologies of people who don't? Firsthand experience can also be contrasted with what one infers and with what one assumes, as in Matses, an Amazonian language, "I infer that ..." or "I conjecture that ...," which is not the same for Matses speakers as implying uncertainty as in "... might have ..." (Fleck, 2007, cited in Aikhenvald, 2014). For the Matses speaker and listener, a person saying "I infer" or "I guess" means that the speaker is certain, whereas "might have" implies uncertainty. And these evidentials are all morphemes rather than separate lexical items. If English speakers were constantly encoding through verbs, as speakers of some Amazonian languages do, whether the information was witnessed firsthand, whether it was inferred or assumed, whether it was reported, and whether we have internal support (which in Matses is a gut instinct taken to mean by the speaker and the listener that that which the speaker asserts must be so) (Lowe, 1999, cited in Aikhenvald, 2014), our ability to speak about - and possibly reason about - the sources of our knowledge and beliefs might be different.

\section{Cultural Aspects of Knowledge and Reason}

Knowledge and reasoning are related in that we use knowledge to reason about the world. Cultural expectations may have consequences for people's willingness to reason about events they have not experienced - and therefore have no direct knowledge of - themselves. Schooling is a cultural intervention that has been found to affect people's willingness to reason about events unfamiliar to them. For instance, an oftcited example in cultural psychology was reported by Luria based on his work in the 1930s with Central Asian peasants. He presented adults with a syllogism as follows:

In the Far North, where there is snow, all bears are white. Novaya Zemlya is in the Far North and there is always snow there. What color are the bears there?

Luria reported that schooled, literate participants solve the problem in the expected way. However, many of the unschooled, nonliterate participants did not. One unschooled participant said, "We always speak only of what we see; we don't talk about what we haven't seen." After probing, the participant said, "Well it's like this: Our tsar isn't like yours, and yours isn't like ours. Your words can be answered only 
by someone who was there, and if a person wasn't there he can't say anything on the basis of your words." When pressed further, the participant explained that a person who had seen a white bear could talk about it and be believed but that he himself had "never seen one and hence ... can't say. That's my last word. Those who saw can tell, and those who didn't see can't say anything!" (Luria, 1976, pp. 108-109). The interviewer clearly had a different view about what kind of evidence is required to report something as knowledge. A similar pattern has been found in unschooled individuals in other cultural groups such as the Kpelle of Liberia (Cole, Gay, Glick, \& Sharp, 1971) and the Maya and Mestizo peoples of the Yucatán peninsula in Mexico (Sharp, Cole, \& Lave, 1979); people who have been to school tend to be willing to engage in syllogistic reasoning independent of personal firsthand knowledge, but those who have not been to school are more likely to draw upon their experience and ignore the logical proposition and its implications. Schooling, however, does not guarantee that people will be good at logical reasoning; even highly schooled participants can have trouble with formal logic when they are biased by information they know to be true and they ignore the validity of the proposition (Evans, Handley, \& Harper, 2001; Galotti, 1989).

\section{Knowledge: For What Purpose?}

Another sociocultural variable related to knowledge is its purpose. What is knowledge good for, and how should it be used? For those more individualistically oriented, knowledge is disengaged from social contexts. In more collectivistic orientations, knowledge has a social purpose, is embedded in social experiences, and mediates social relationships (Rothstein-Fisch, Greenfield, \& Trumbull, 1999). Culture also affects how one should display knowledge. Among European Americans, the squeaky wheel gets the grease, while in Japan the nail that stands out gets pounded down; hence, verbally and even boastfully demonstrating one's knowledge is acceptable in certain settings in the USA, while quiet observation and modesty are considered markers of intelligence in Japan (Greenfield \& Suzuki, 1998).

\section{Historical Contexts of Knowledge}

The historical context in which we use knowledge is a factor in epistemology, particularly as it relates to what one considers to be appropriate sources of authority. Currently we have at our fingertips a source of information and knowledge that is seemingly infinite - the Internet - but how can we be sure the information we are accessing is correct? It is critical that we understand what knowledge is, where it comes from, how to find correct sources for different kinds of knowledge, how to triangulate sources, and how to build and revise a knowledge base in the mind. Otherwise what may look like knowledge may end up being useless to us in the pursuit of truth and in solving problems. The women in the study were in their late thirties and early forties at the time they were interviewed, and their PEs arguably reflect a certain point in historical time and the attendant goals, values, and emotional messages of that time. How might the PEs of women in a different cohort - 19-year-old women now or 40 -year-old women in 50 years - vary because of influences like the Internet? 


\section{Knowledge and Gender}

Why study women's epistemologies in particular? How could ways of knowing be different across genders? Women's PEs are important to understand because PEs develop as situated practices in sociocultural activities and settings. Aspects of settings include values and goals (Gallimore, et al., 1993), and the messages girls and women may receive in settings may differ from the ones received by boys and men. And it is possible that the scripts for behavior that are indicated as appropriate for women may lead women to adopt epistemological stances that cause them to see things differently, to talk and to reason about things differently than men. Women may develop habits of asserting or not asserting their beliefs and knowledge. Knowing how women develop epistemological habits can help us understand how epistemology and the construction of knowledge work more generally.

Because Tafreshi and colleagues (this issue) deal only with women at one point in time, we do not get a sense of how these women differ from men, nor do we know why some women's PEs might be more influenced by empathy, emotion, self-understanding, and relationships to authority, as the authors assert, than are men's. PEs tell more of the story of why there are individual differences in voicelessness or a range of assertiveness of voice among women, but we also need to look at factors that influence women's experience of voicelessness. Where do those ideas come from, and why do some women internalize those more than others? If women have trouble finding a voice, why? These are questions worth exploring culturally and developmentally. Are there settings in which men have trouble finding a voice? On the other hand, are there people who always feel like they have a voice and will talk about anything, even if they know nothing about it? Much emphasis has been placed on women's voices and the findings that show that the ways that women see things may not be the same as the way men see things. Men, too, may be finding their voices in certain settings and activities, particularly when those settings and activities are unfamiliar. While being a newcomer is not the same as feeling that one has no voice, we do not think that voicelessness is solely experienced by women.

While understanding the PEs of women and other groups is important, we believe we should articulate theories about people's development and behavior with an eye for broadening our explanations to include more experiences rather than creating explanations that silo different people's experiences and reify terminologies that cultivate divisions. That is, we should use what we know about women's PEs to expand our thinking about epistemology more generally, not just about women. We think that this will lead to more inclusion and a deeper understanding of development and the human experience, adding to a more coherent story of how the mind works based on the experience of diverse groups.

\section{Enlightenment Principles Today}

How are knowledge and the search for it reinforced today? If you are reading this article, you believe that the mind is intelligible and knowable, and you are, we hope, curious about the different kinds of methods that let the mind reveal itself to us more fully and accurately. The exploration of different ways of knowing reveals information about how our minds work at the same time as it reveals our minds as part of - 
influenced and shaped by our experiences in - the world we inhabit. If we use science to allow the world to tell us whether or not our ideas about it are correct (Pinker, 2018), we are engaging in constructive knowing and epistemology that can change in coordination with new information and experiences. The alternatives - believing in all powerful beings that control our lives or sticking with ideas in the face of contradictory information because an authority figure says to - lead to erroneous reasoning and dangerous thinking. A PE that is in between - subjective knowing - was exhibited by one participant in the data presented by Tafreshi and colleagues: Tara blamed her university education for her "muddy" thinking that there is no objective truth. She left the university before graduating, so perhaps some of the blame is on her, but this may still be an issue in university settings. While "victimization" by the university setting is in itself an idea of received knowing, Tara is not alone in thinking that there is "no truth" to be found because there are so many competing theories and because "science changes anyway." In a number of disciplines, professors are teaching the idea that there is no objective truth (Pinker, 2018); this would certainly muddy thinking about knowledge and what counts as knowledge. We would be wise to help our students and each other contemplate the idea that there are certain truths, for example that "life is better than death, health is better than sickness, abundance is better than want, freedom is better than coercion, happiness is better than suffering, and knowledge is better than superstition and ignorance" (Pinker, 2018, p. 452) - all Enlightenment principles based in the ideals that reason and science - which require us to examine underlying epistemological stances - are essential in understanding the world and our minds as part of it.

\section{References}

Aikhenvald, A. Y. (2004). Evidentiality. Oxford, England: Oxford University Press.

Aikhenvald, A. Y. (2014). The grammar of knowledge: A cross-linguistic view of evidentials and the expression of information source. In A. Y. Aikhenvald \& R. M. W. Dixon (Eds.), The grammar of knowledge: A Cross-linguistic typology (pp. 1-51). Oxford, England: Oxford University Press. doi:10.1093/ acprof:oso/9780198701316.003.0001

Belenky, M. F., Clinchy, B., Goldberger, N., \& Tarule, J. (1986). Women's ways of knowing: The development of self, voice, and mind. New York, NY: Basic Books.

Boas, F. (1942). Language and culture. In S. H. Cross (Ed.), Studies in the history of culture: The discipline of the humanities (pp. 178-184). Menasha: George Banta Publishing.

Cole, M., Gay, J., Glick, J. A., \& Sharp, D. W. (1971). The cultural context of learning and thinking: An exploration in experimental anthropology. New York, NY: Basic Books.

Evans, J. S. B., Handley, S. J., \& Harper, C. N. (2001). Necessity, possibility and belief: A study of syllogistic reasoning. The Quarterly Journal of Experimental Psychology: Section A, 54(3), 935-958. doi: $10.1080 / 713755983$

Fleck, D. W. (2007). Evidentiality and double tense in Matses. Language, 83(3), 589-614. doi:10.1353/ lan.2007.0113

Gallimore, R., Goldenberg, C. N., \& Weisner, T. S. (1993). The social construction and subjective reality of activity settings: Implications for community psychology. American Journal of Community Psychology, 21(4), 537-559. doi:10.1007/BF00942159

Galotti, K. M. (1989). Approaches to studying formal and everyday reasoning. Psychonomic Bulletin \& Review, 105(3), 331-351. doi:10.1037/0033-2909.105.3.331

Greenfield, P. M., \& Suzuki, L. (1998). Culture and human development: Implications for parenting, education, pediatrics, and mental health. In I. E. Sigel \& K. A. Renninger (Eds.), Handbook of child psychology: Vol. 4. Child psychology in practice (5th ed., pp. 1059-1109). New York, NY: Wiley. 
Hofer, B. K. (2001). Personal epistemology research: Implications for learning and teaching. Journal of Educational Psychology Review, 13(4), 353-383. doi:10.1023/A:1011965830686

Kuhn, D. (1999). A developmental model of critical thinking. Educational Researcher, 28(2), 16-26. doi: 10.3102/0013189X028002016

Lowe, I. (1999). Nambiquari. In R. M. W. Dixon \& A. Y. Aikhenvald (Eds.), The Amazonian languages (pp. 269-292). Cambridge, England: Cambridge University Press.

Luria, A. R. (1976). Cognitive development: Its cultural and social foundations. Cambridge, MA: Harvard University Press.

Maynard, A. E. (2009). Context and structure in social interaction and cognitive development. Human Development, 52(5), 313-319. doi:10.1159/000233262

Pinker, S. (2018). Enlightenment now: The case for reason, science, humanism, and progress. New York, NY: Viking Press.

Rothstein-Fisch, C., Greenfield, P. M., \& Trumbull, E. (1999). Bridging cultures with classroom strategies. Educational Leadership: Race, Class, and Culture, 56, 64-67.

Sharp, D., Cole, M., \& Lave, C. (1979). Education and cognitive development: The evidence from experimental research. Monographs of the Society for Research in Child Development, 44(1-2), 1-112. doi: $10.2307 / 3181586$ 